Research Article

\title{
Restoration and Strengthening of Historical Buildings: The Example of Minceta Fortress in Dubrovnik
}

\author{
Jure Radnić $(\mathbb{D}$, Domagoj Matešan $(\mathbb{D}$, and Ante Abaza \\ Faculty of Civil Engineering, Architecture and Geodesy, University of Split, Split, Croatia \\ Correspondence should be addressed to Jure Radnić; jure.radnic@gradst.hr
}

Received 20 May 2020; Revised 2 September 2020; Accepted 13 September 2020; Published 30 September 2020

Academic Editor: Melina Bosco

Copyright (C) 2020 Jure Radnić et al. This is an open access article distributed under the Creative Commons Attribution License, which permits unrestricted use, distribution, and reproduction in any medium, provided the original work is properly cited.

Firstly, some important aspects of the restoration and structural strengthening of historical masonry buildings are briefly discussed. Particularly, as an illustration of the appropriate approach to solving such an issue, an example of the restoration of the Minceta fortress in Dubrovnik has been described. Based on the results of the extensive field and laboratory works with defined damages and cracking state in the fortress, as well as located sliding surfaces in foundation rock near deep excavation, the static and dynamic analysis of stress-strain states and safety was performed at the characteristic time point in the history of the fortress. Different geometry models for discretization of the fortress and the foundation rock, as well as different constitutive models for masonry and rock, were considered. Based on the results of the case study, the solutions were proposed for the strengthening of the foundation rock, as well as for the restoration and the limited allowed strengthening of the fortress. It is believed that this study may be helpful in the restoration and strengthening of similar historical masonry structures.

\section{Introduction}

A large number of diverse historical buildings in the world require restoration. Due to the demand for their great seismic resistance, as well as for other reasons, there is a need to strengthen their structures. As historical buildings are particularly complex and require detailed preservation of their original historical forms (architectural, artistic, structural, etc.) and also their building materials, the restoration and strengthening of historic buildings are extremely complex and demanding. It particularly refers to the restoration and strengthening of load-bearing structures of historical buildings, presenting a major challenge for structural engineers.

Historical buildings are predominantly built of stone and brick, i.e., their structures are predominantly masonry. Due to the mechanical characteristics of such materials and loadbearing structures of masonry elements, while taking into account the many restrictions required by architectural, conservational, and other objective requirements, the restoration and strengthening of historical buildings can be performed only by experienced and creative structural engineers.
So far, a large number of papers have been published with the topic of structural restoration and strengthening of historical buildings. An overview of several such papers is listed below.

Various numerical techniques and models with different complexities and accuracies for the static and dynamic analysis of masonry structures are presented [1-11]. Different methodologies for the structural restoration of historical buildings are described [12-15]. The acquired experience on the analysis and strengthening of numerous buildings in Italy after the recent earthquakes were also useful for this study [16-20]. The interdisciplinary study [21], the nondestructive tests, and the tests performed on the shake table [22-24] were also used in the analysis of the damages and the strengthening for complex masonry buildings. Also, different studies about structural analysis of historical building along with their numerical modelling are reported [25-29].

In this paper, some important aspects of the restoration and strengthening of historical buildings are briefly discussed in Section 2, and then the issue of restoration of the Minceta fortress in Dubrovnik is presented in Section 3. The 
results of the case study of the damages of the fortress are presented in Section 3.1, and then the results of static and dynamic analysis of stress-strain states and safety of the fortress using different numerical models are described. In Section 3.2, the solutions for the restoration and strengthening of the fortress are briefly presented. The main conclusions of the study are presented in Section 4.

It is believed that the presented methodological approach to detecting all the restoration issues and solving them, as shown with an example of the restoration and strengthening of the Minceta fortress, can help in the renovation of other historical buildings.

\section{Some Aspects of the Restoration and Strengthening of Historical Buildings}

The restoration of historical buildings includes the renovation of their various original solutions in terms of shape and size, architectural style, construction, bearing structures, materials, functionality, aesthetics, etc. Some of these buildings near the Adriatic Sea in Croatia are shown in Figure 1. Numerous historical buildings have been built throughout long years, with various forms, construction styles, building materials, supporting systems, and purposes. Some of the historical buildings have been subjected to severe actions during the years, which have significantly altered their original purpose, load-bearing structure, and appearance. The construction of new buildings or interventions nearby some historical buildings, significantly affected the safety and sustainability of historical buildings in some cases.

Most historical buildings are built of stone and/or brick. Such buildings should have specific load-bearing systems, considering the fact that masonry structures are not capable of carrying any tensile forces, or insignificantly. As a rule, the masonry structures should have such load-bearing systems where tensile forces in the structure do not occur for dead and live loads or are small. Unfortunately, many historical buildings, with all praise to their builders, do not have the most optimal load-bearing systems where only compression forces occur or dominate in structures, namely, the preferred load-bearing systems of masonry structures are arches, vaults, domes, massive walls, and massive columns (Figure 2). They should be of such size that, even in the case of small tensile forces (cracks), the stability and safety of such elements are ensured, as well as the stability and safety of the entire building.

In seismically active areas, the historical masonry buildings have often been subjected to numerous strong and sometimes devastating earthquakes. This often led to severe damages or collapse of such buildings because their builders did not predict such actions, namely, the earthquake causes large horizontal forces which produce large bending and shear in the vertical structural elements of the masonry building. They are often not capable of withstanding strong earthquakes, thus causing severe damage and even their collapse. The historical masonry buildings are usually massive and of heavy weight. Being proportional to weight of buildings, the seismic forces are very large on such buildings.
Given its large initial (elastic) stiffness, i.e., a small free oscillation period of masonry structures at the beginning of the earthquake, large seismic inertial forces are induced. However, because of the sudden and large decrease of initial stiffness due to the occurrence of cracking, slipping and other nonlinearities cause the earthquake energy dissipation and the significant reduction of earthquake forces in the masonry structure. On the other hand, the multiple static indeterminacy of the complex load-bearing system of the masonry building usually leads to a redistribution of the internal forces in the structural elements and contributes to higher load-bearing capacity of such structures. This is the reason that the stone structures are often capable of standing even stronger earthquakes than expected on the basis of simple calculations, which is commonly confirmed by complex numerical analysis.

In order to reduce the seismic forces on buildings and the stresses in the soil below foundations, in many cases, the experienced builders use lightweight materials of lower strength in higher parts of the building and heavy materials with greater strength in lower parts. So the lower parts in many historical stone structures are made of high-quality stone blocks with larger volume weight and the taller parts (usually less loaded arches, vaults, and domes) of porous less resistant blocks with small volume weight (Figure 3 ). Because of the simplicity and faster construction, the size of stone blocks is regularly reduced through the height of the building. The use of stones with less volume weight in the arch structures was often motivated by the need for a simpler scaffold in their construction.

One of the basic structural characteristics of arches, vaults, and domes is the presence of the horizontal forces on supports. If the forces are at ground level and the soil has the adequate lateral bearing capacity with the limited lateral deformability, there will be no negative consequences on the building structure and they can be relatively easily transferred to the soil (Figure 4). If the soil is laterally deformable, it can cause shifting of the arch abutments and the appearance of cracks and damages in the arch structure. Particularly unfavourable is that the abutments of the arches, vaults, and domes are at a higher height above the ground, i.e., when being supported by high walls/columns. In this case, it is necessary that the peripheral supports of such arches are sufficiently massive (heavy) and rigid walls/columns which can transfer the horizontal forces to the soil without damage. In complex and tall stone structures, it is extremely important that the composition of the arches/ vaults/domes with different spans and heights, combined with the stiffness/mass of walls and columns, be designed so that the compression forces dominate for the basic loads and smaller tension forces for earthquakes.

It should be noted that the bearing ability of the masonry walls and columns subjected to shear and bending, i.e., carrying horizontal forces, directly depends on the size of the axial compressive force in them. If it tends to zero, their shear and bending bearing capacities disappear. In case of the increased horizontal force on the walls/columns, they should have higher compressive axial force and greater stiffness. Thereby, it should be ensured that the allowable 


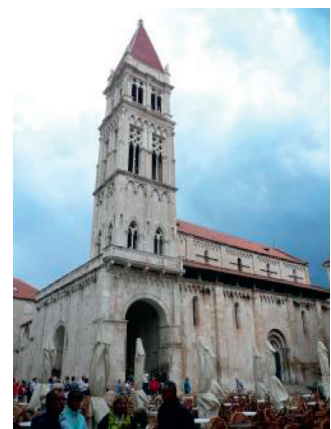

(a)

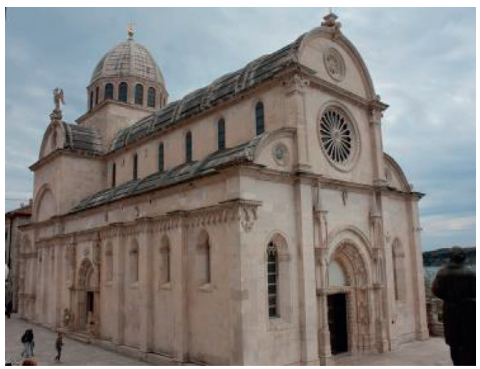

(d)

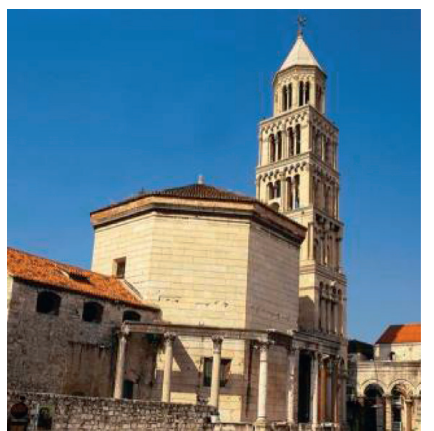

(b)

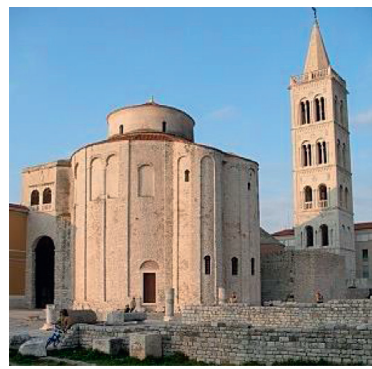

(e)

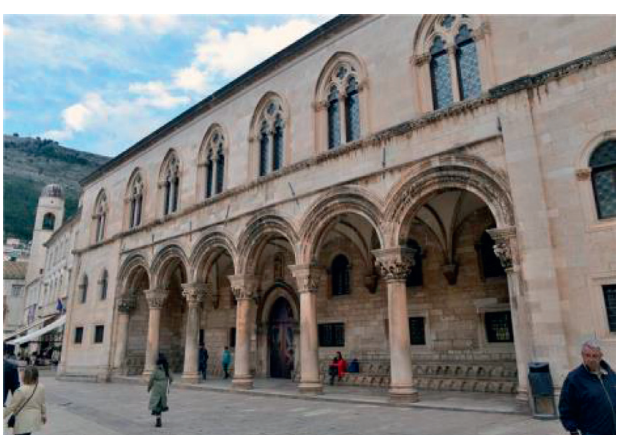

(c)

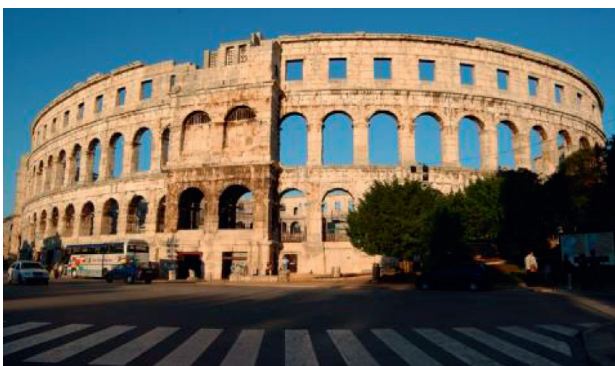

(f)

Figure 1: Some historical buildings in Croatia. (a) The Cathedral in Trogir. (b) The Cathedral in Split. (c) The Rector's Palace in Dubrovnik. (d) The Cathedral in Šibenik. (e) The Church of St Donatus in Zadar. (f) The Amphitheatre in Pula.

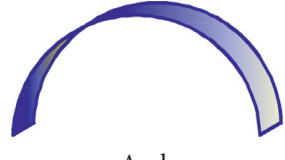

Arch

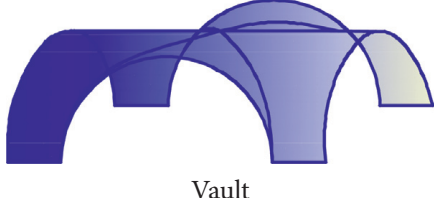

(b)

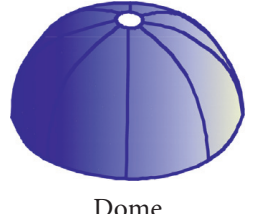

(c)

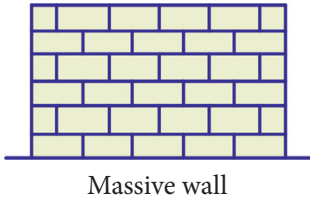

(d)

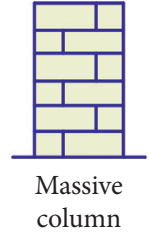

(e)

FIGURE 2: The schemes of preferred load-bearing systems of masonry structures. (a) Arch (b) Vault. (c) Dome. (d) Massive wall. (e) Massive column.

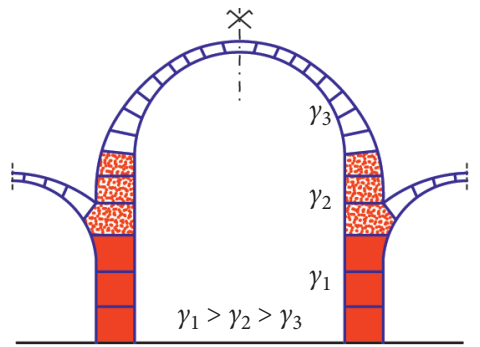

FIGURE 3: The scheme of favourable mass distribution (strength) and block size along height of historical building.

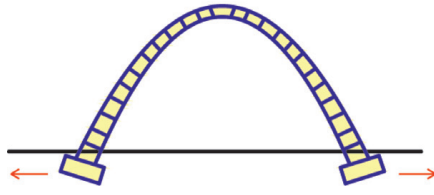

Favourable

(a)

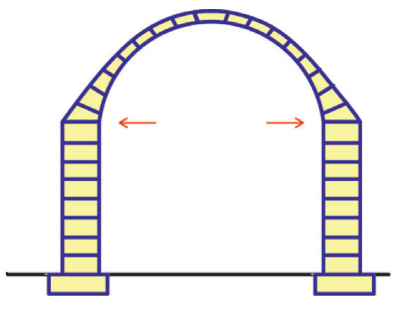

Unfavourable

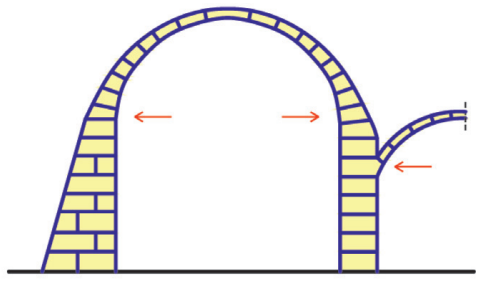

Favourable

(b)

FIGURE 4: The schematic positions of supports of arch (vault, dome) along height of building. (a) Above the foundations. (b) At the top of the walls. 
compressive bearing capacity of the wall and the soil is not exceeded.

All buildings, including the historical ones, interact with the foundation soil. The effect of soil-foundation interaction is particularly significant if differential settlement and rocking of the foundation is possible, especially during the earthquake. Since the tensile forces cannot be transferred on the contact surface between the foundations and the soil, the uplift of the structure from the ground, the stiffness changing (the appearance of nonlinearity), and the reduction of the seismic forces in the structure occur in this case. In earthquake action, an alternating cyclic effect can occur and so-called the rocking motion can appear.

In many historical masonry structures, a lime mortar was used for the joints between masonry elements. $\mathrm{Nu}$ merous historical buildings have been restored being completely or partially repaired by cement-lime mortar or even pure cement mortar, considering that such buildings will be more resistant to earthquakes and more rigid for other loads and actions. Unfortunately, as a rule, this is not the case, namely, the cement mortar has significantly lower ductility (deformability) in the tensile failure. Consequently, in the cement mortar joints, the cracking appears at lower tensile strains in relation to the lime mortar joints. In this case, the cracks' widths in the cement mortar joints are much higher than in the lime mortar joints. Since the cement mortar provides greater stiffness of the masonry structure than the lime mortar, such construction will attract larger seismic forces. Although such a structure has a higher tensile resistance, due to larger seismic forces, it will faster exceed the tensile strength and cracking appearance in the cement mortar joints than in the lime mortar joints. Due to the increased stiffness, the masonry structures built with cement mortar are more susceptible to differential settlement of its foundations than the same with lime mortar.

Uniform and nonuniform temperature variations in a masonry structure are common cause of cracks and damages, especially when the building is larger and stiffer. In this regard, the dry joints between masonry elements are more favourable because they can deform more freely in different directions, and a change of joint width due to temperature dilatations is generally not visually expressed. When the mortar is used for joining the masonry elements, exceeding the tensile strains/stresses in the joints due to temperature variations, it can lead to the cracks in the joint. Hence, the cement mortar was also less favourable than lime mortar.

For the restoration of historical masonry structures, the materials and elements with significantly different temperature coefficients in relation to those of the masonry are sometimes used. If they are coupled, temperature variations may cause unexpected and undesirable damage of the original masonry structure. As a general rule, the coupling of such materials/elements for the classical masonry structures should be avoided.

In historical buildings where the interior walls are plastered, they can be significantly strengthened by using a new (typically lime) reinforced plaster. Certain structural elements can sometimes be reinforced with modern materials (carbon strips and fabrics, straps, wire ropes, etc.), which should usually be unnoticeable.

The stone columns are often present in numerous historical masonry buildings, whether they are major structural or desirable aesthetic elements (Figure 5). Unfortunately, many such columns are damaged by earthquakes, due to material degradation over time, temperature changes, etc. Their restoration is usually complex and demanding. Short columns are often constructed from a massive block, and tall columns from several blocks (so-called multidrum columns). The behaviour and load-bearing capacity of multidrum columns depend on numerous factors [30, 31]. By increasing the number of blocks (joints) in the multidrum columns, the load-bearing capacity for static forces and impact earthquake forces decreases, thus increasing the seismic bearing capacity for earthquakes that generate large displacements and large energy. The rigid joints between stone blocks (filled with mortar, etc.), compared to soft joints (dry, filled with stone powder, etc.), enable greater loadbearing capacity of the multidrum stone column under static load and so-called impact earthquake, and lower loadbearing capacity in the case of earthquake with higher energy. The columns with the dowels between the stone blocks significantly increase the load-bearing capacity of multidrum columns under earthquake excitations, while the diameter and the length of the dowels, as well as the dowels material, and the diameter of the hole may have smaller or bigger effects on the bearing capacity of such columns.

Many historical buildings have a wooden roof structure (Figure 6). It is particularly desirable that its structure system does not transfer the horizontal forces to the substructure under dead and live loads. It is also desirable that the wooden structure be stiff in its plane and protected from moisture and pests.

The structural restoration of each historical building is specific, both in a global solution and in the solutions of particular details. Therefore, it is first necessary to study its basic properties and analyse its deficiencies and damages and examine the properties of the basic materials. In this respect, it is important to carry out a detailed range of necessary field and laboratory works. Only after the completion of the necessary analysis, all the appropriate solutions of restoration/rehabilitation/reconstruction of buildings can be defined and developed, and then all adequate computational verifications and evidences can be carried out. As an instructive example, a solution to the restoration of the Minceta fortress in Dubrovnik has been described below.

\section{Restoration of the Minceta Fortress in Dubrovnik}

\subsection{Study of the Fortress Damages and Safety}

3.1.1. Basic Data of the Fortress. Dubrovnik is one of the UNESCO World Heritage Sites in Croatia. The Minceta fortress is a unique symbol of Dubrovnik being located in the north-western corner of famous city walls (Figure 7(a)). The top of the fortress is the highest and the most prominent part of the city walls (Figure 7(b)). With its position and size, it 


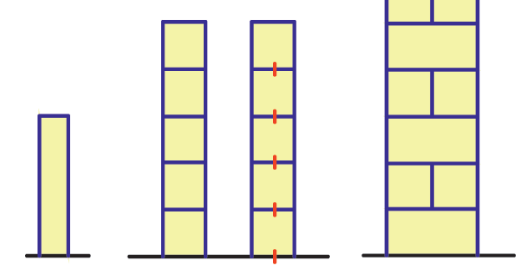

One block
Several blocks along height

(a)

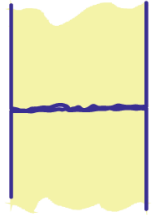

Dry sand, etc.)

(b)

FIgURE 5: Some schemes of the stone columns and the types of joints. (a) The number and arrangement of blocks. (b) The joints.

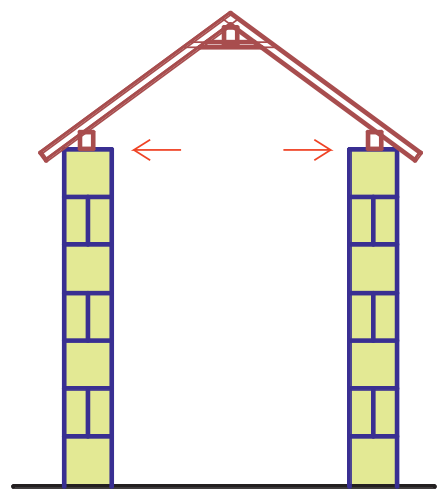

(a)
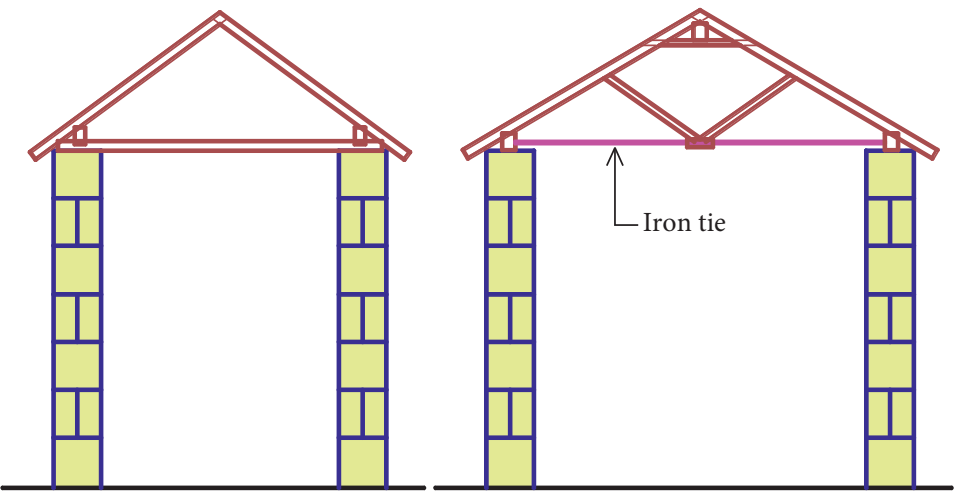

(b)

FIgURE 6: Some schemes of the wooden roofs of historical buildings. (a) Unfavourable. (b) Favourable.

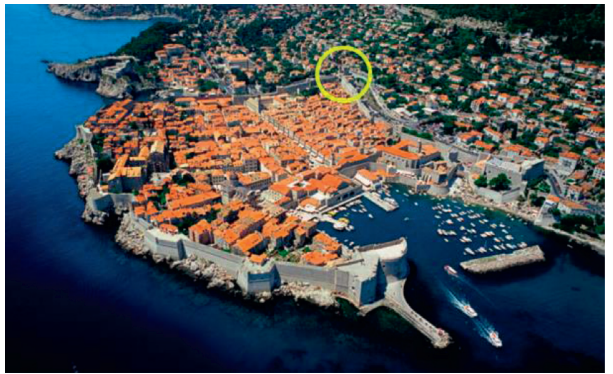

(a)

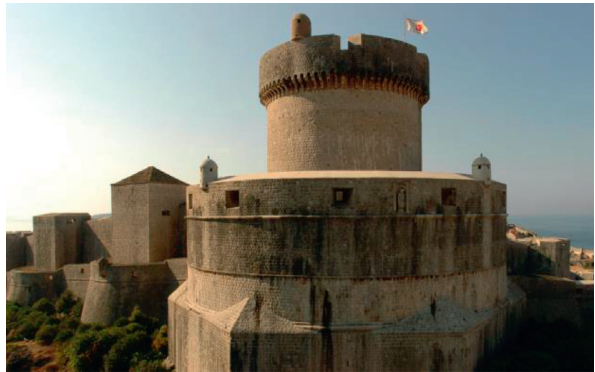

(b)

Figure 7: Dubrovnik and the Minceta fortress. (a) Dubrovnik, with the location of the Minceta fortress marked. (b) A view of the Minceta fortress from the north-west [32].

dominates the north-western part of the old city having been highly important point of its defence in history.

Dubrovnik is located in a seismic zone with possible catastrophic earthquakes, some of which have already occurred in its history. The Minceta fortress has been damaged and rehabilitated several times in its centuries of history. At the end of the eighteenth century, the deep cut for the city road was excavated, that significantly destabilised the fortress. The fortress has some safety and stability issues in the present state, although at first sight, it is in a relatively good state because it has been partially renovated throughout the whole period.
The vertical cross section through the fortress in the north-south direction is shown in Figure 8(a), and a floor plan at the zero level is presented in Figure 8(b). The main parts of the fortress are the old tower, the prewalls and the new tower. Only the interior of the old medieval tower, with an inside height of $12 \mathrm{~m}$, and the south facade are still preserved. The prewalls were built in a circular form with an outside diameter of $35 \mathrm{~m}$ and a height of $16.3 \mathrm{~m}$. The prewalls have three levels. The zero level has central and peripheral corridors and five radially placed casemates. The first level has a peripheral corridor and nine casemates. The second level is infilled with earth and stone. Above the second level, 


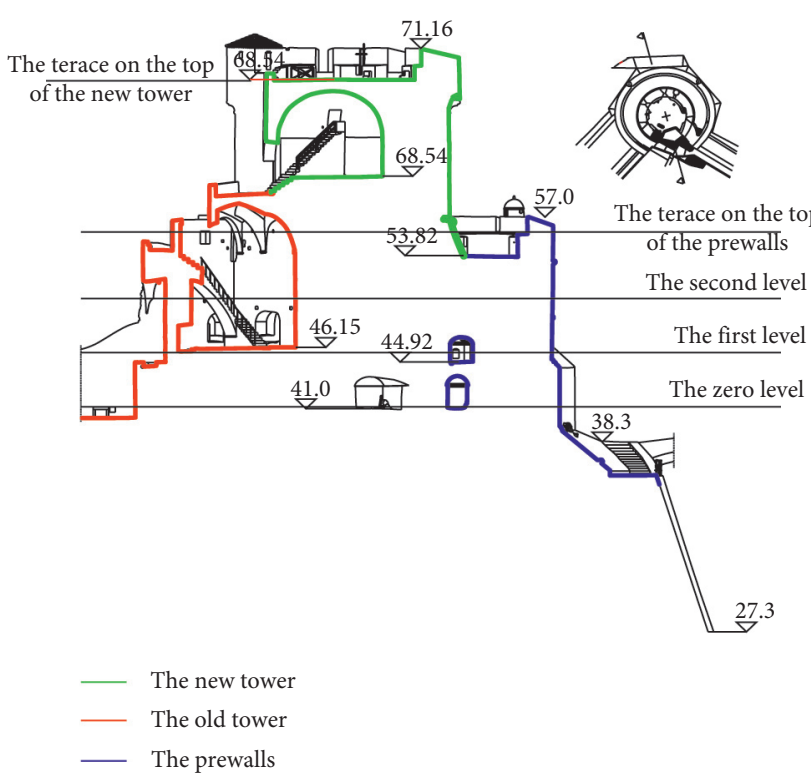

(a)

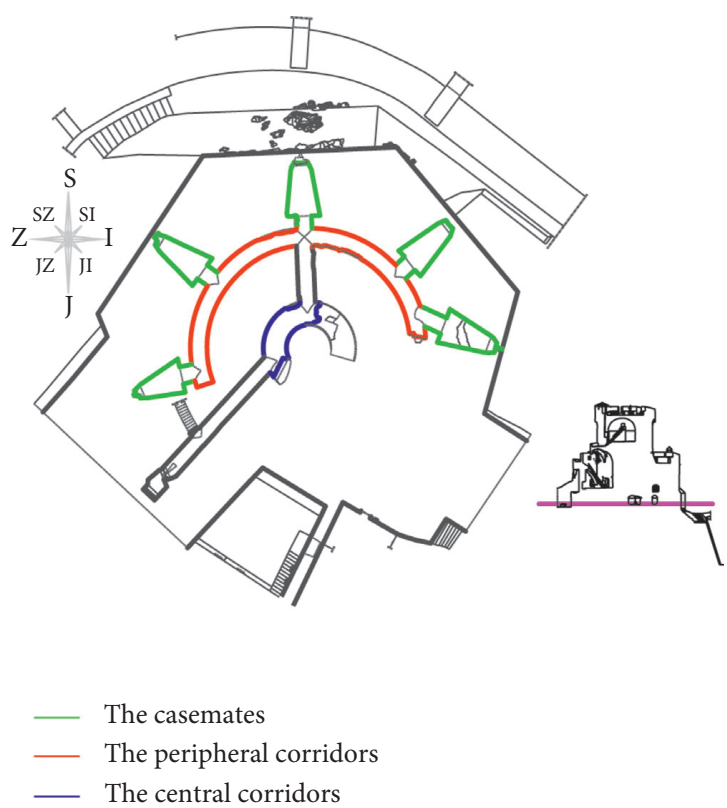

(b)

Figure 8: Vertical cross section (a) and floor plan at the zero level (b) of the Minceta fortress.

there is the terrace surrounded by the prewalls, at a height of $3.4 \mathrm{~m}$, and a thickness of $2.8 \mathrm{~m}$, with nine openings for guns and the walkway.

The new tower rises from the middle of the prewalls, with a diameter of approximately $18 \mathrm{~m}$ and a height of $7.3 \mathrm{~m}$. The bottom part of the tower is inclined, the central part is upright and the upper part protrudes outward as a cantilever. The domed atrium of the tower has a diameter of $8 \mathrm{~m}$ and a height of $7 \mathrm{~m}$. The terrace at the top of the new tower is surrounded by a defensive wall with four holes for cannons and two guard houses.

The Minceta fortress was built over a long period of time. The design of the first medieval tower was made in 1319 [33]. The tower was completed in 1343. The largest part of today's fortress was built in the fifteenth century.

First, the old square tower was strengthened. The zero level of the tower was infilled with stones and a lime mortar in 1453, while the upper part of the tower was raised to $3 \mathrm{~m}$. The tower was rounded during 1455 by the prewalls on the three levels surrounding the existing tower. The height of the old tower was probably reduced during the building of the new tower. The second level of the prewalls was infilled in 1646 due to the strengthening of the fortress defence.

A large portion of Dubrovnik was destroyed in 1667 during a strong earthquake of intensity $\mathrm{X}$. The massive city walls and the fortifications did not collapse in the earthquake for the most part, but suffered extensive damages [34]. The exact damages of the Minceta fortress were not specified. Obviously, the fortress damages were not extensive compared to the damages of other buildings having been noted for repairs. Immediately after the earthquake, a fire followed lasting for 20 days. In total, approximately 3000 people died, which was then half of the city's population.
The road around the city was breached at the end of the eighteenth century, which significantly destabilised the fortress (Figure 9(a)). Landslides soon followed along the slopes of the deep cut, which were stabilised by the three stone struts across the cut and by the slope protection with the stone cladding.

The wider Dubrovnik region was badly damaged in the disastrous Montenegro earthquake in 1979 [35], of intensity IX-X. The earthquake's power in Dubrovnik was of intensity VII. Additionally, the Dubrovnik region was strongly damaged during the Ston earthquake in 1996 [36], of intensity IX. It is not known whether the Minceta fortress suffered any damages from these earthquakes.

In the twentieth century, there were no the significant restoration works on the Minceta fortress. The joint repairs on the facade of the fortress were performed on several occasions in the last 15 years. The larger and better quality restoration works were carried out in 2002. The high-quality repairs to the stone cantilevers on the top of the new tower were completed in 2009.

3.1.2. The Main Observed Defects and Damages of the Fortress. The rock layers below the fortress near the deep cut have an unfavourable slope inclination toward the road threatening the stability of the fortress (Figure 9(a)).

Numerous cracks in the walls and the vaults of the old tower were observed. The south wall of the tower is very slender and its stability is questionable.

At the zero level of the fortress, numerous cracks in the vaults (Figure 9(b)) and the walls of the patrol corridors and casemates were also observed. The wide cracks in the ceiling of the corridor and the walls (Figure 9(c)) were probably caused by shifts in the underlying rock. The sliding of almost 


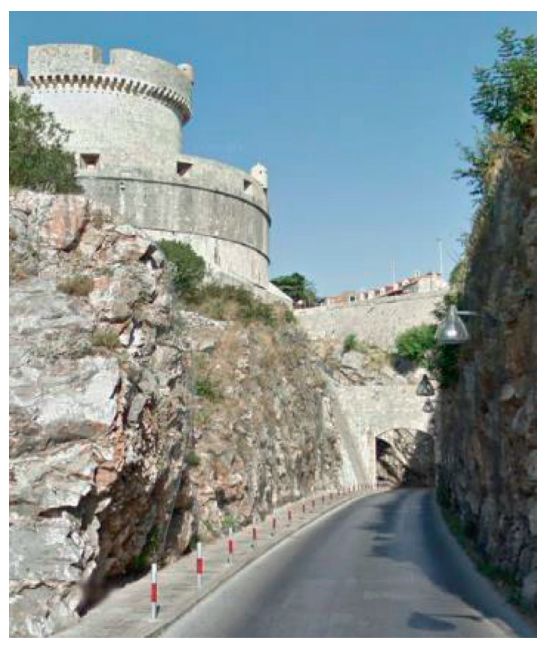

(a)

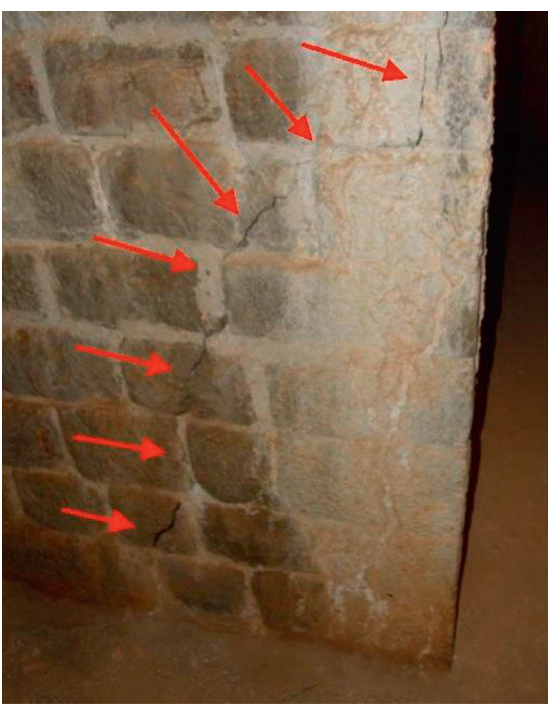

(c)

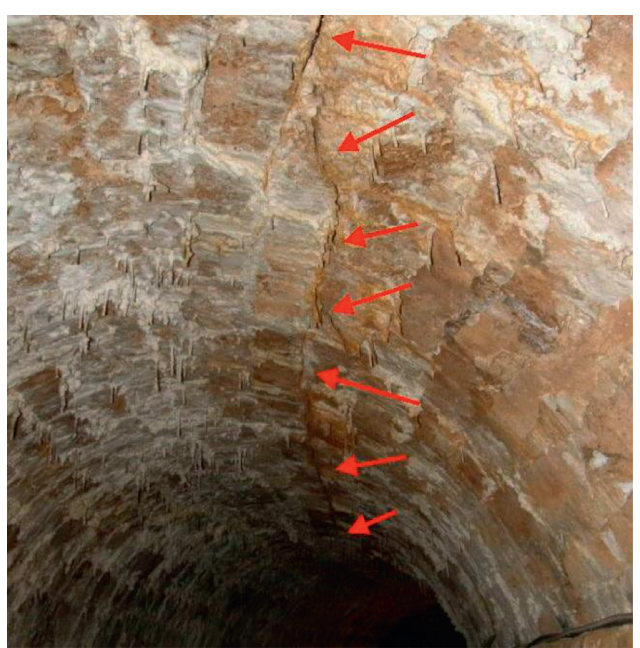

(b)

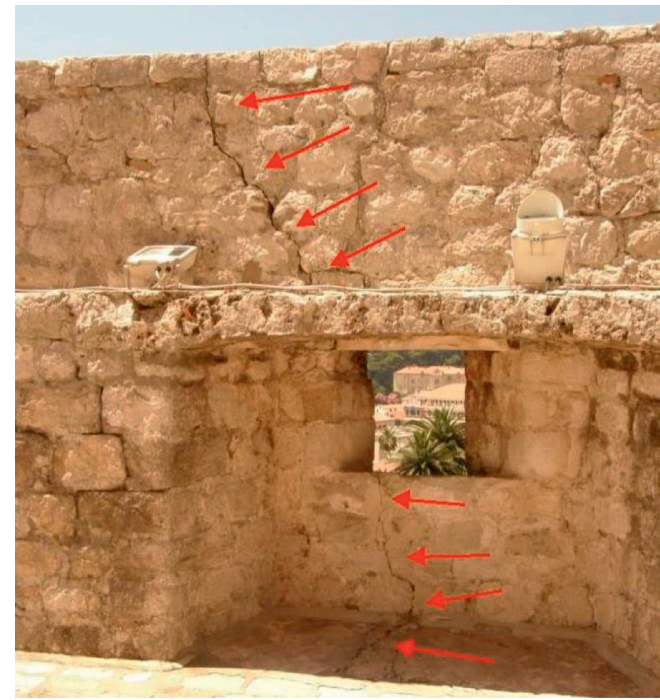

(d)

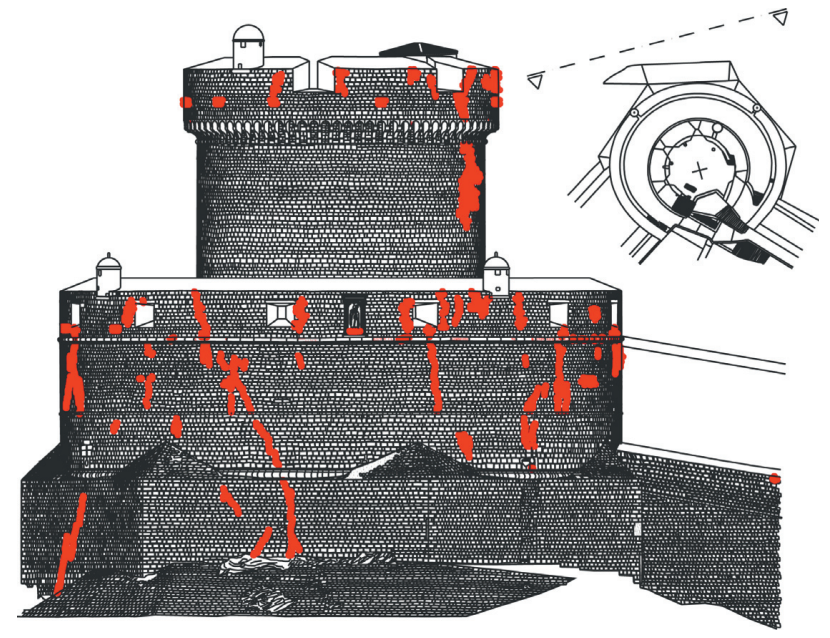

(e)

Figure 9: Some defects and damages of the fortress. (a) The deep cut on the northern side of the fortress. (b) Typical cracks in the vaults of the patrol corridors and casemates at the zero level. (c) The broken piece of the wall corner in the peripheral corridor at the zero level. (d) Typical cracks in the prewall around the gun opening above the terrace. (e) The marked cracks in the north-western facade of the fortress. 
half of the prewalls towards a deep cut was caused by this shift. The breaking apart of the prewalls and their slipping towards the deep cut are associated by the direction and the width of the cracks.

On the first level of the fortress, similar cracks to the zero level were observed. The wide cracks and their directions in the northern and western parts of the prewalls show the sliding towards the cut.

Cracks were also observed in the prewalls around the gun openings (Figure 9(d)). The cracks extend along the entire height of the wall in several places. Consequently, the outer surfaces of the prewalls are cracked in several locations from the bottom to the top being fractured into several separate parts.

The new tower is visually well preserved in relation to the rest of the fortress because it was recently repaired. The joint grouting between the stone blocks and the replacement of the damaged stone cantilever on top of the tower have been involved in rehabilitation activities. The cracks in the terrace on the top of the tower were also observed. The breaking apart of the tower into separate parts has been possible. The north-western facade of the fortress with the current cracks is shown in Figure 9(e).

3.1.3. Field and Laboratory Works. The extensive field and laboratory works were performed to determine the mechanical properties of the fortress masonry and the top of the foundation rock at the zero level, as well as the geotechnical and geophysical properties of the rock below the tower. More details can be found in [37].

The compressive strength of the top of the rocks below the tower are in the range of 15 to $60 \mathrm{MPa}$, and the compressive strength of the stone blocks of the fortress are 60-90 MPa. The infill between the external stone blocks of lime and crushed stone has a compressive strength of 10-15 MPa. The compressive strength of the mortar in the joint between the stone blocks is $12-17 \mathrm{MPa}$. These values were determined by the standard test procedures for determination of compressive strength of masonry units and mortar HRN EN 772-1:2015 and HRN EN 1015-11:2019, respectively.

The mechanical properties of the rock mass required for the static and dynamic analysis of the fortress were determined by the geotechnical and geophysical investigations. Rock layering toward the deep cut was observed, which is very unfavourable. Relaxation of the rock mass after the excavation of the deep cut was noticed.

3.1.4. The Stress-Strain and Safety Analysis of the Fortress. The stress-strain state and safety of the fortress before and after the road breaching on the north and west sides of the fortress were analysed. The fortress and the underlying rock were included in the geometry model. The stability of the underlying rock mass toward the deep cut was analysed. The relevant load cases and actions were considered (dead load, temperature variations, modal analysis, and static and dynamic earthquake analysis). The strongest earthquakes expected to occur at the location of the fortress were counted for a return period of 475 years and the maximum design spectral acceleration is $0.3 \mathrm{~g}$ according to EN 1998 (EC 8). In the dynamic analysis, the fortress was analysed for the Stone earthquake from 1996. The different models used a different approximation of the geometry $(1 \mathrm{D}, 2 \mathrm{D}, 3 \mathrm{D})$ and stiffness of the structure, as well as different constitutive models of the masonry and the foundation rock (linear and nonlinear). The used nonlinear computational model [38] simulates the main nonlinear effects of the masonry and rocks, such as the opening and closing of cracks in tension, the nonlinear behaviour in compression, the tensile and shear stiffness of the cracked material, the nonlinearity on the contact, and the anisotropy of the materials.

The graphical presentation of the used nonlinear numerical model [38] is presented in Figure 10. The so-called macro model for the masonry and the rock was adopted. The cracks were modelled as smeared. The adopted discrete elements between the fortress and the rock can simulate the sinking, the uplift, and the sliding of the interface surface. The effect of the large displacements was also included. The dynamic equation was solved by an implicit Newmark algorithm. The adopted numerical model has been verified using experimental and numerical tests of other models [38] and can be considered reliable.

Based on the results of the experimental tests and adopted partial safety coefficients, the material parameters for the numerical analysis were adopted according to Table 1 . The parameters of the masonry in brackets refer to the state after the restoration and strengthening of the fortress. The values of the parameters in Table 1 are within the usual limits for similar historical buildings [38].

Only some results are presented in this paper: the displacement, compressive stresses, and tensile strains. The displacements for the nonuniform temperature distribution of 10 degrees Celsius at the south side and 0 degrees Celsius at the north side are shown in Figure 11(a). The vertical stresses for the dead load are shown in Figure 11(b), and the vertical stresses for the dead load and the earthquake accelerations of $0.3 \mathrm{~g}$ (equivalent static analysis) are shown in Figure 11(c). The first four mode shapes and eigenvalues of the numerical model are shown in Figure 11(d). Figure 11(b) shows that the average vertical compressive stresses from the dead load at the level of the bottom of the fortress (the top of the foundation rock) are relatively small and equal to $0.5 \mathrm{MPa}$. The stresses at the same position for a combination of dead load and earthquake forces of acceleration $a=0.3 \mathrm{~g}$ are $2.4 \mathrm{MPa}$ (Figure 11(c)). Figure 11(d) shows that the frequency of oscillations for Model 1 is $4.36 \mathrm{~Hz}$, i.e., $T_{1}=0.23 \mathrm{~s}$, so it can be specified that the fortress fits to the rigid masonry structures according to EN 1998 (EC 8), that generate the huge earthquake inertial forces.

Some results for time history analysis under the Stone earthquake are presented in Figure 12. Figure 12(a) shows some global displacements at $t=5.85 \mathrm{~s}$ and $t=6.20 \mathrm{~s}$. Figure 12(b) shows the principal tensile strains (cracking zones) at $t=6.2 \mathrm{~s}$. Figure $12(\mathrm{c})$ shows some characteristic displacements at the top of the tower and bottom of the fortress over time before and after the excavation of the deep cut. 


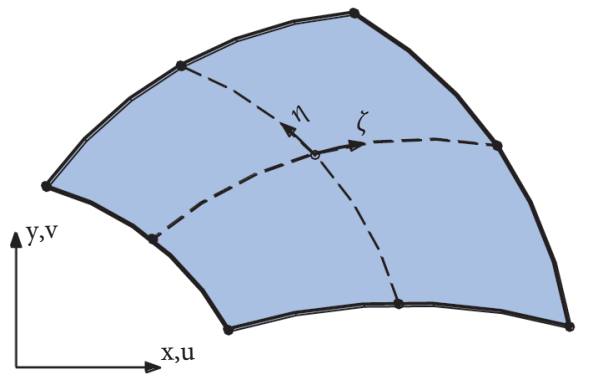

2D basic element

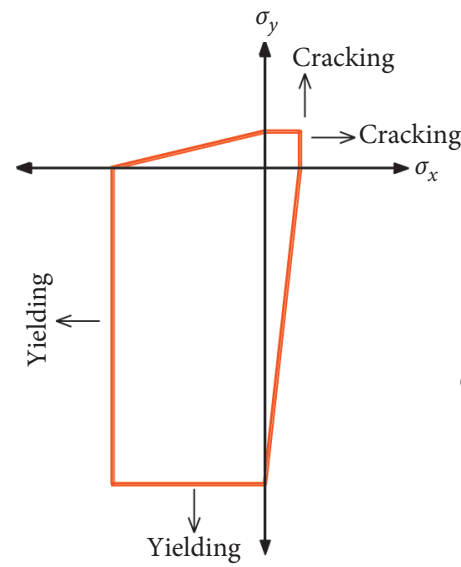

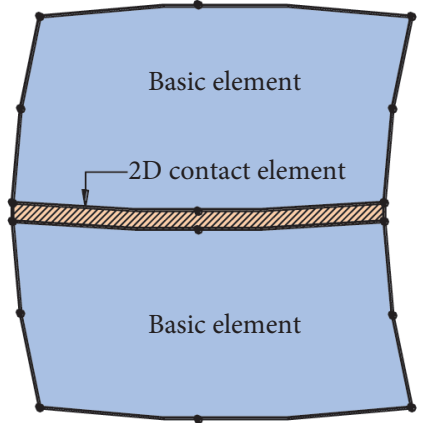

2D contact element

(a)

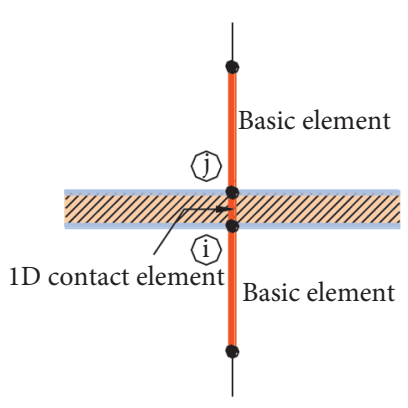

1D contact element

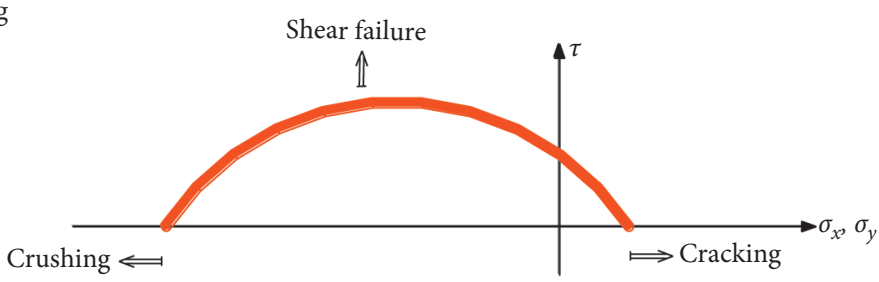

(b)
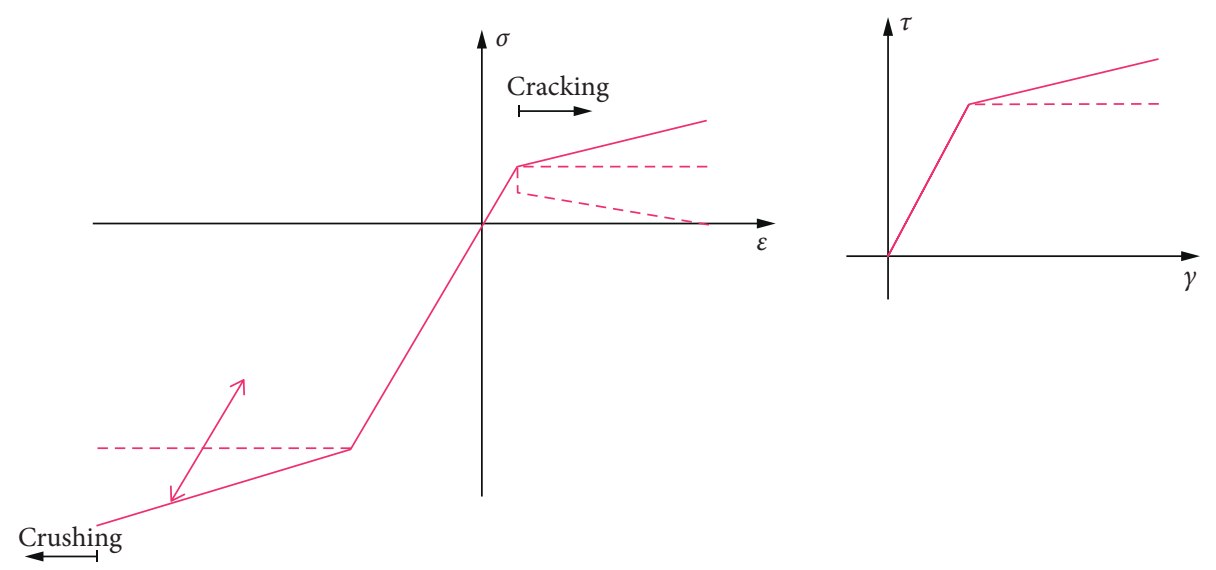

(c)
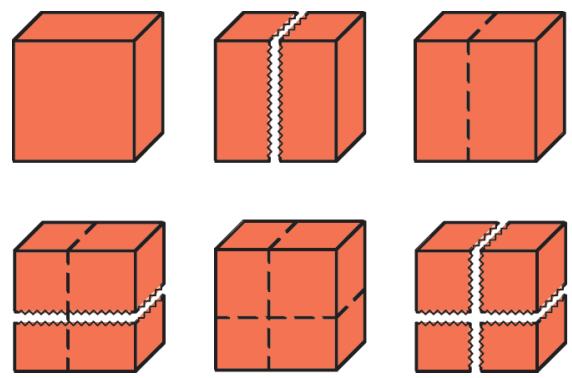

(d)

FIgURE 10: The graphical presentation of the adopted 2D nonlinear numerical model: (a) finite elements, (b) constitutive model for basic materials, (c) constitutive model for contact elements, (d) possible crack patterns [38]. 
TABLE 1: Material parameters of rock and masonry used in the numerical analysis.

\begin{tabular}{lccc}
\hline \multirow{2}{*}{ Parameters } & \multicolumn{2}{c}{ Foundations rock } & Masonry \\
& Weakened rock & Healthy rock & $4000(5000)$ \\
Elasticity modulus (MPa) & 4000 & 5000 & $3,2(4,0)$ \\
Compressive strength (MPa) & 4,5 & 5,0 & $0,17(0,2)$ \\
Tensile strength (MPa) & 0,1 & 0,2 & $0,12(0,15)$ \\
Poisson's coefficient & 0,15 & 0,12 & 0,05 \\
Damping coefficient & 0,06 & 0,05 & 05 \\
\hline
\end{tabular}

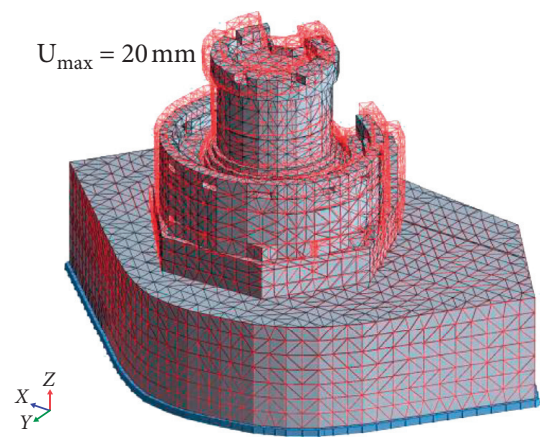

(a)
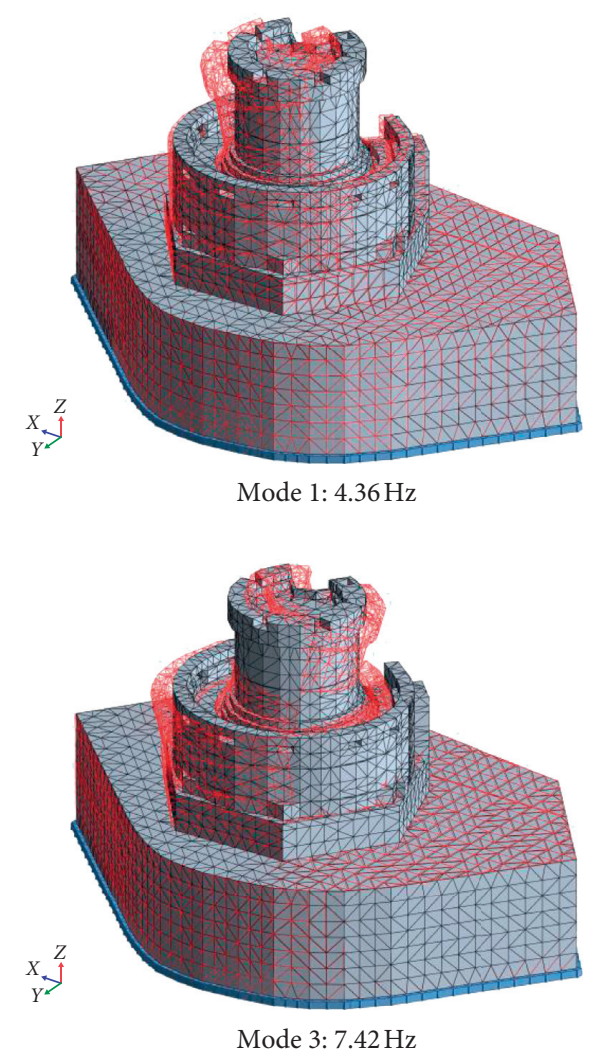
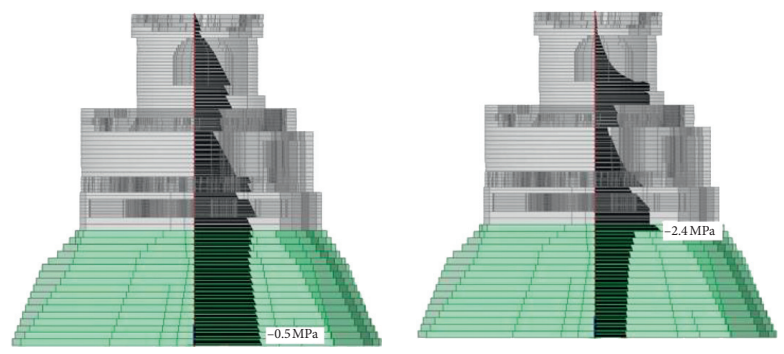

(c)
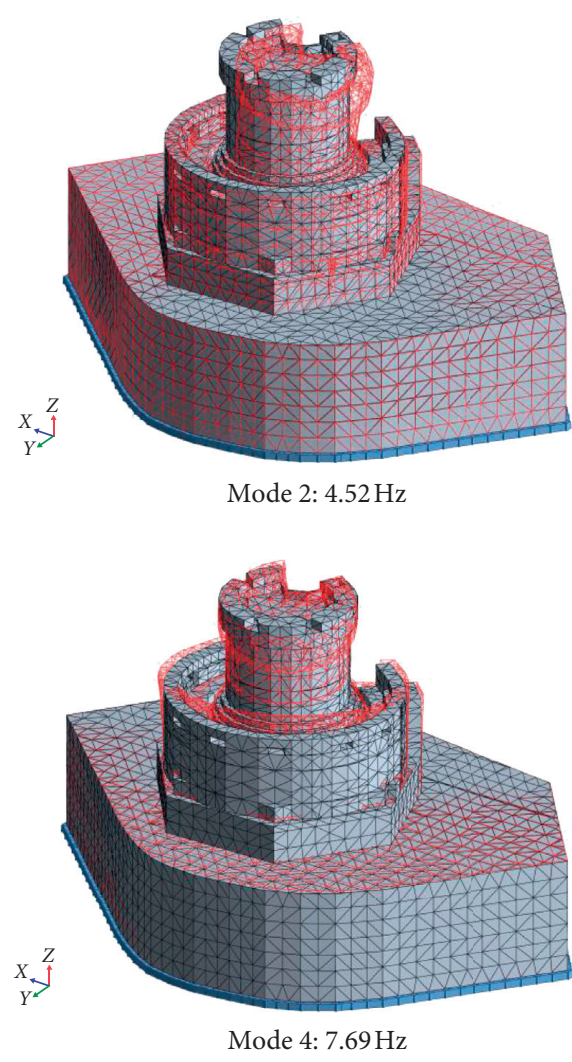

(d)

FiguRE 11: Some results of finite element analyses. (a) The displacements for the nonuniform temperature distribution of $10^{\circ} \mathrm{C}$ at the south side and $0^{\circ} \mathrm{C}$ at the north side. (b) The vertical stresses for the dead load (MPa). (c) The vertical stresses for the combination of the dead load and the earthquake forces for an acceleration of $0.3 \mathrm{~g}(\mathrm{MPa})$, equivalent static analysis. (d) The first four mode shapes and eigenvalues of the numerical model.

The stresses for the dead load in the assumed sliding surface of the rock below the fortress toward the deep cut are shown in Figure 13. Figure 13(a) shows that the normal stresses perpendicular to the sliding surface are compressive, which is favourable; however, when they are relatively small, it is unfavourable. Figure 13(b) shows that the shear stresses 

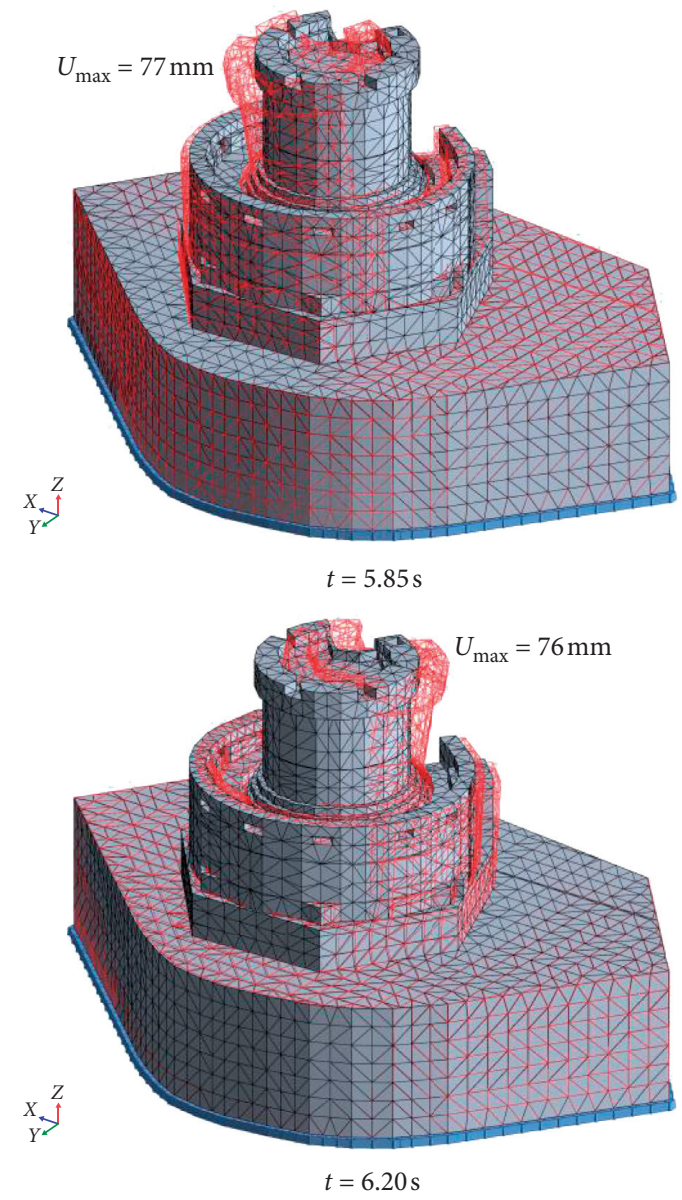

(a)

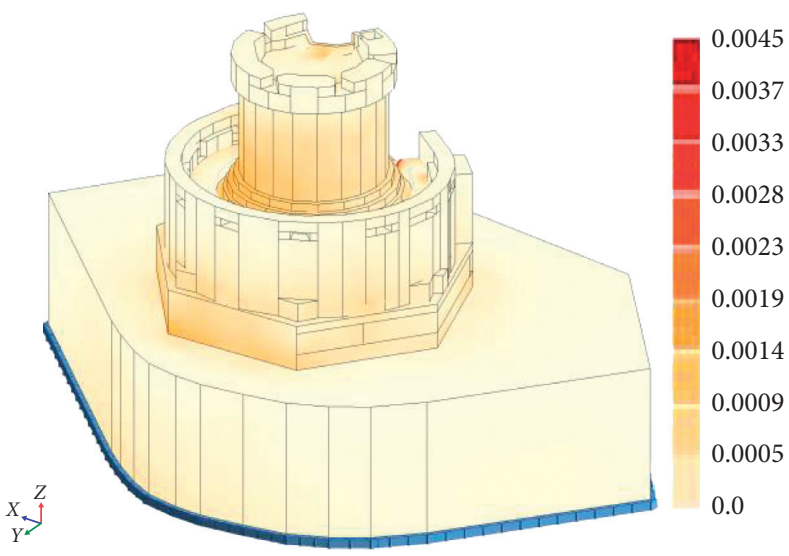

(b)

Figure 12: Continued. 


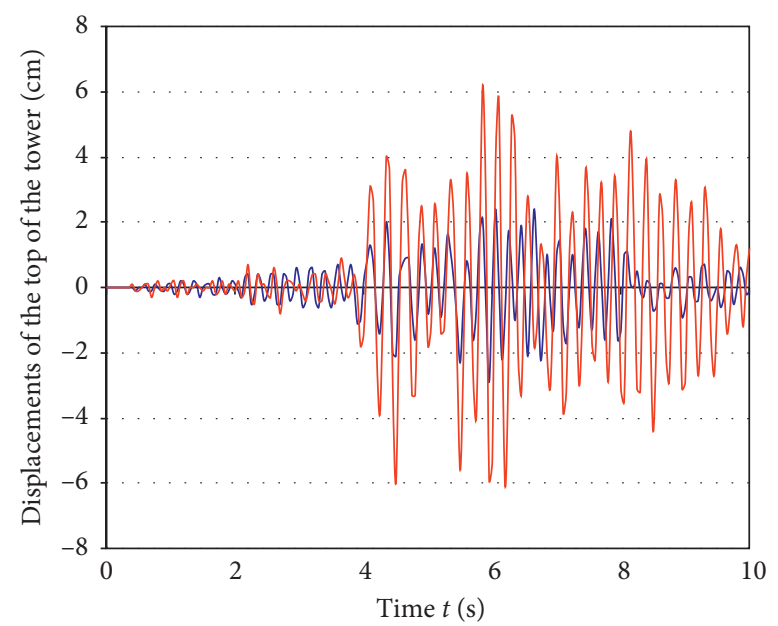

- $U y(\mathrm{~cm})$ - before the deep cut

- $U y(\mathrm{~cm})$ - after the deep cut

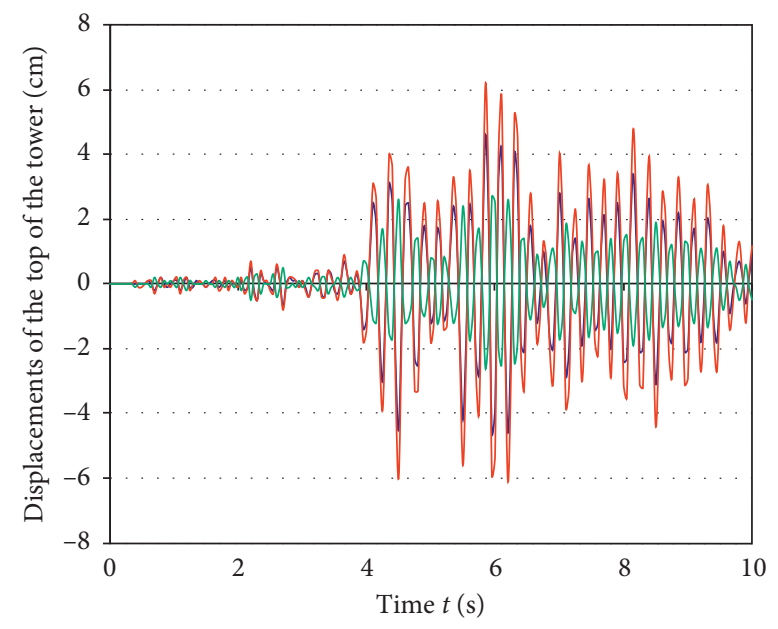

- $U x(\mathrm{~cm})$ - after the deep cut

- $U y(\mathrm{~cm})$ - after the deep cut

- Uz (cm) - after the deep cut

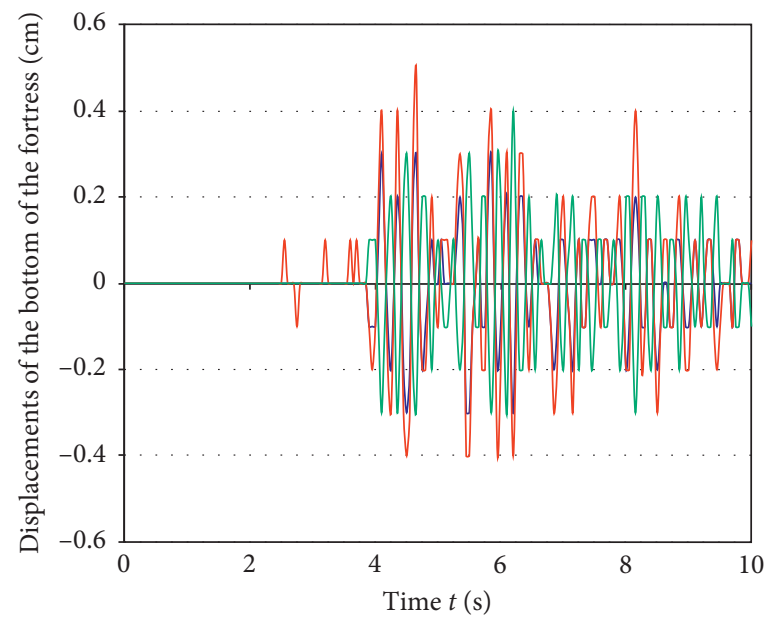

$U x(\mathrm{~cm})$ - after the deep cut

- $U y(\mathrm{~cm})$ - after the deep cut

- Uz $(\mathrm{cm})$ - after the deep cut

(c)

Figure 12: Some results for time history analysis under the Stone earthquake. (a) Some global displacements for the Stone earthquake at $t=5.85 \mathrm{~s}$ and $t=6.20(\mathrm{~s})$. (b) The principal tensile strains (cracking zones) at $t=6.2 \mathrm{~s}$ for the Stone earthquake, view from the north. (c) Some characteristic displacements of the north-western facade of the fortress over time for the Stone earthquake. 


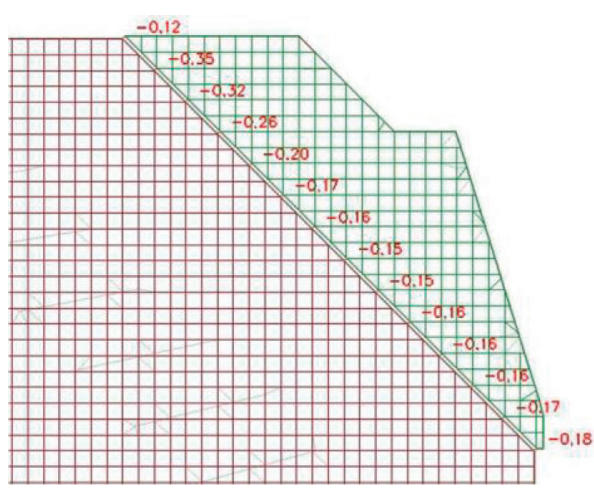

(a)

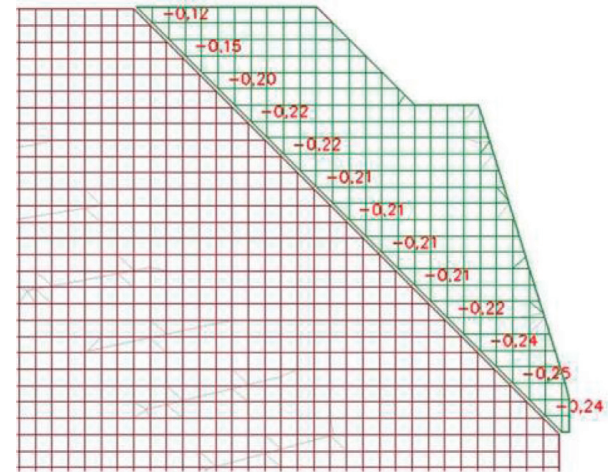

(b)

FIgURE 13: The stresses $(\mathrm{MPa})$ in the assumed sliding surface of the rock for the dead load: (a) normal stresses, (b) shear stresses.

in-plane of the sliding surface are big, which is very unfavourable.

3.1.5. The Main Finding of the Study. Numerous cracks in the walls and vaults of the fortress were observed, particularly on the prewalls. The widest cracks are at the locations of the wall openings. The old tower is heavily damaged, and the stability of the south wall is especially threatened.

In a structural sense, all of the openings in the body of the fortress are the weak spots. The corridors and casemates at the zero and first level are almost overlapping (Figure 14(a)), resulting in continuous weakening and vulnerability of the fortress to vertical splitting in the direction of the weaknesses.

The large horizontal cracks in the ceiling of the peripheral corridors at the zero level and the vertical crack over the entire northern facade likely indicate the breaking apart of the northern prewalls into the blocks. The assumed global breaking apart of the fortress is shown in Figure 14(b).

The fundamental rock below the fortress near the deep cut is cracked and adversely layered. At that location, the rock sliding surfaces are probably already formed. The assumed rock sliding surface and the breaking apart of the prewalls are shown in Figure 14(c).

The existing drainage system at the top of the fortress tower and at the terrace of the prewall top has not been well constructed, which has allowed water to leak into the fortress interior.

The wider zones of the cracks in the masonry of the fortress may occur only for the temperature actions.

The fortress cannot withstand the maximum design ground acceleration of $0.3 \mathrm{~g}$ and exceeds the stability design requirements.

The deep cut along the western and northern edges of the fortress significantly reduced its stability.

In regard with the Stone earthquake considered in this study, the fortress did not collapse, but it was strongly damaged.

The calculated maximum compressive stress in the masonry of the fortress for Stone earthquake was approximately $8.0 \mathrm{MPa}$, and the maximum displacement of the fortress top was approximately $77 \mathrm{~mm}$.
Some parts of the fortress suffered severe structural damage under the adopted earthquakes (lintels above the opening, some vaults, the southern wall of the old tower, the outdoor cantilevered walls of the prewalls above the second level, etc.).

The rock massif near the deep cut is not safe against the sliding, even for only gravity loads. An imminent risk of the collapse of the rock massif was prevented by the previous construction of three struts such as the stone arches.

The next strong earthquake could be fatal for the stability of the slopes of the deep cut and the fortress. An adequate increasing of the rock massif stability near the deep cut is urgently needed.

Restoration and strengthening of the fortress are urgently required. The water leaking into the fortress on the top of the tower and on the terrace of the prewall top must be prevented.

\subsection{The Restoration of the Fortress}

3.2.1. The Strengthening of the Rock Mass near the Deep Cut. Three alternative strengthening solutions for the foundation rock below the fortress near the deep cut are proposed: (i) the tunnel, (ii) the additional struts, and (iii) the rock slope stabilization by the ground anchors.

(i) The tunnel structure would support the opposite slopes of the deep cut and stabilize the cliff below the fortress, which would provide a permanent and reliable solution. Thus, the original appearance of the fortress and the city walls on that location before the road excavation would be restored. A new city area of approximately $3000 \mathrm{~m}^{2}$ for parking and other facilities would be created.

(ii) In addition to the three existing stone struts, four new struts should be built. This solution would be visually perceived as a tunnel. It would be more rational than the tunnel construction but without the possibility of creating a valuable city area, and it would be less favourable than the conventional tunnel. 


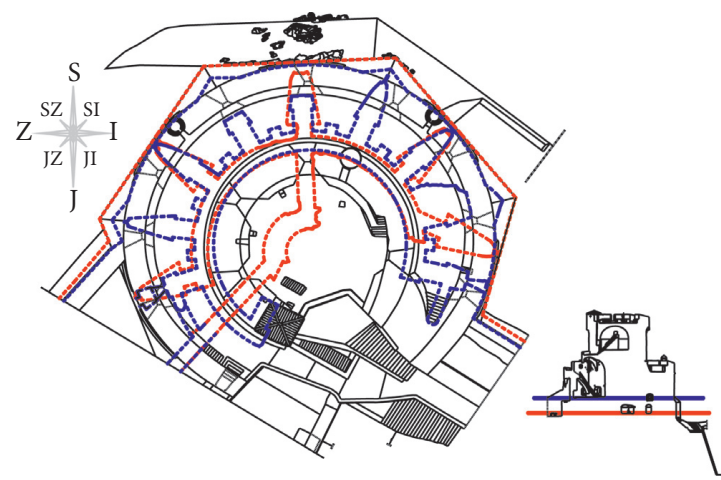

(a)
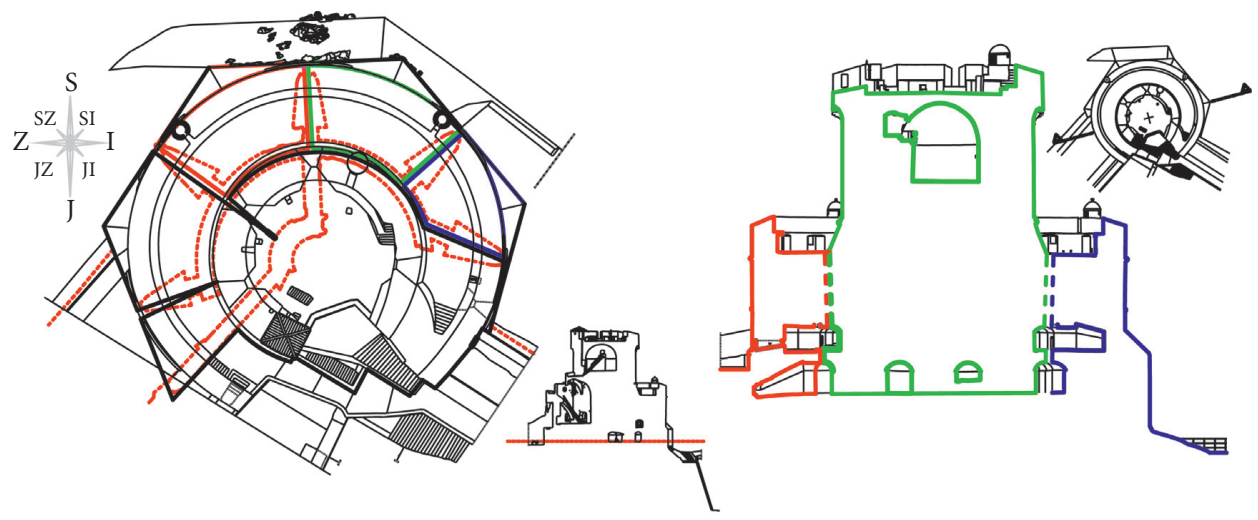

$\equiv \equiv \equiv$ The assumed cracking

” The assumed global breaking apart

(b)

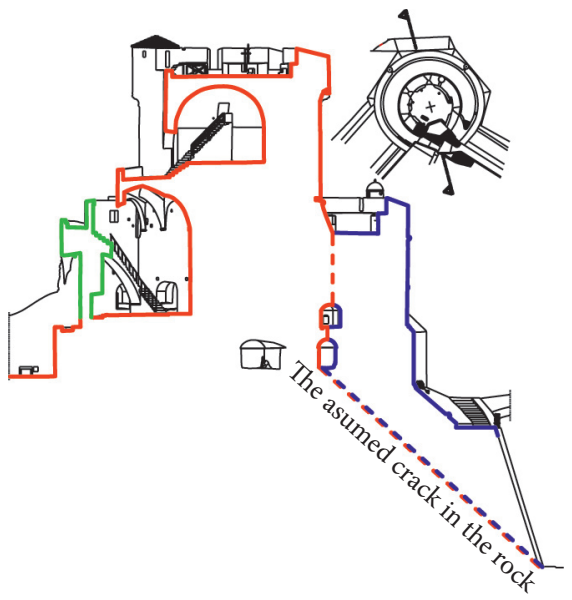

$==\mathbf{=}$ The assumed cracking

․ The assumed global breaking apart

(c)

FIGURE 14: The assumed global cracking pattern, breaking apart, and sliding rock surface. (a) The overlapping of the corridors and casemates at the zero and first levels. (b) The assumed global breaking apart of the fortress. (c) The assumed sliding rock surface and the breaking apart of the prewalls.

(iii) The strengthening of the cut slope by concrete beams and ground anchors would be visually unacceptable and insufficiently reliable. In addition, the unfavourable seismic effect of the deep cut on the fortress stability would not be reduced, and the durability of such a solution would be limited due to the potential danger of the corrosion of the ground anchors in a wet environment. This solution is considered as the least acceptable among the proposed ones. 


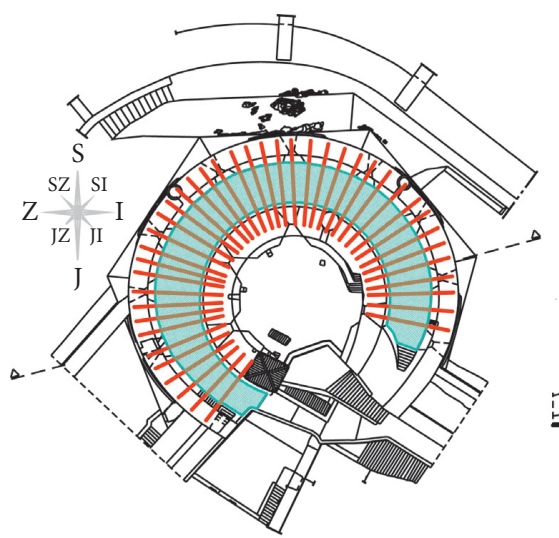

Fibre strands

Clay membrane

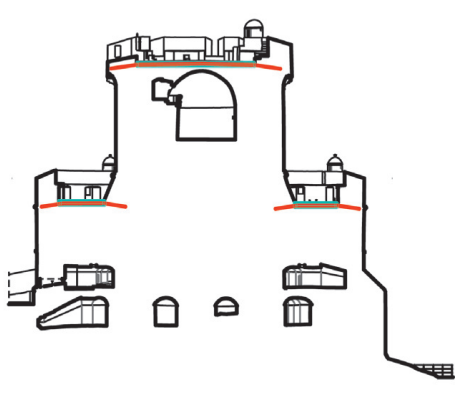

(a)

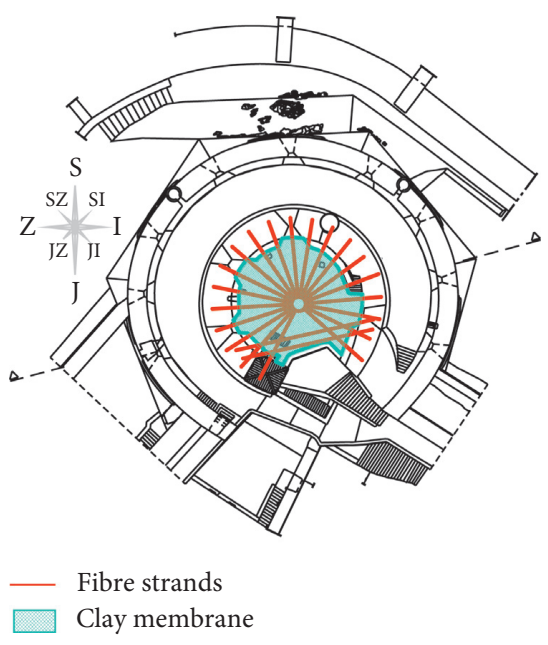

(b)

FIGURE 15: The position of the glass fibre strands for stiffening the tops of the fortress: (a) the terrace on top of the prewalls, (b) the terrace on top of the new tower.

3.2.2. The Restoration and Strengthening of the Fortress. The restoration of the fortress and its allowed limited strengthening included the following main works:

(i) Grouting of the cracks in the walls and vaults that are wider than approximately $2 \mathrm{~mm}$.

(ii) Jointing between the stone blocks along the cracks and in the locations of the worn joints using lime mortar.

(iii) Stiffening of the south wall of the old tower by upgrading the southern boundary city wall.

(iv) The construction of soft diaphragms for stiffening the fortress at the level of the open terraces on top of the prewalls and at the level of the terrace on the tower top, with the improvements of the system for precipitation water drainage. The position of the glass fibre strands that are anchored in the peripheral walls at the previously mentioned levels is shown in Figure 15.

All rehabilitation solutions have been previously consulted by the city administration and conservators-restorers.

3.2.3. Numerical Analysis of the Restored Fortress. In the numerical tests for the restored and strengthened fortress, the masonry parameters in brackets in Table 1 were used. The strengthened foundation rock below the fortress and towards the deep cut was modelled by the finite elements and the constrained nodes with limited displacements along the cut slope. Some global results of the ultimate bearing capacity of the fortress for their characteristic states in history are presented in Section 4.

\section{Conclusions}

The historic Minceta fortress in Dubrovnik has been severely damaged, with the risk of collapse when it is subjected to even moderate earthquake action. The initial stability reduction of the fortress was caused by the deep excavation along its north-western edge. The adverse layering of the stone cliffs at that location and the gravity load of the fortress caused the shift of the fortress toward the deep cut and the formation of the sliding surface of the rock toward the deep cut. Some of the fortress damage is probably due to the effects of temperature and earlier earthquakes. Urgent improvement of the stability of the foundation rocks below the fortress is necessary. For this purpose, the construction of a common tunnel instead of the deep cut is proposed as an optimal solution. The proposed solution would restore the terrain to the original level creating valuable urban areas. The fortress should be repaired by an adequate grouting of the masonry along the cracks, jointing between the stone blocks along the cracks and by stiffening the weakest parts of the fortress structure. All of the restoration works were consulted by the city administration and conservatorsrestorers.

The following characteristic stress-strain and safety states of the fortress in its history were analysed by finite element method:

(i) The original state before excavation of the deep cut and without fortress damages (the state A)

(ii) The state after excavation of the deep cut and without fortress damages (the state B)

(iii) The state after excavation of the deep cut and with the existing damages of the fortress (the state $\mathrm{C}$ ) 
(iv) The state without the effect of deep cut (foundation rock was fixed), and the restoration and limited strengthening of the fortress (the state D)

The ratio between the ultimate bearing capacity and safety of the fortress was determined approximately as follows: A: B: C: $D=1.00: 0.62: 0.48: 1.18$.

It is believed that the discussion given in Section 2, as well as all presented in Section 3, can be useful in restoration and strengthening of historical structures.

\section{Data Availability}

All data underlying the findings of the study are presented in this article.

\section{Conflicts of Interest}

The authors declare that they have no conflicts of interest.

\section{Acknowledgments}

This work was supported by funds from the Ministry of Science, Education and Sport of Croatia, as well as the Society of Friends of Dubrovnik Antiques. The authors appreciate their financial support.

\section{References}

[1] M. Betti and A. Vignoli, "Assessment of seismic resistance of a basilica-type church under earthquake loading: modelling and analysis," Advances in Engineering Software, vol. 39, no. 4, pp. 258-283, 2008.

[2] P. Foraboschi and A. Vanin, "Non-linear static analysis of masonry buildings based on a strut-and-tie modeling," Soil Dynamics and Earthquake Engineering, vol. 55, pp. 44-58, 2013.

[3] A. Giordano, E. Mele, and A. de Luca, "Modelling of historical masonry structures: comparison of different approaches through a case study," Engineering Structures, vol. 24, no. 8, pp. 1057-1069, 2002.

[4] P. B. Lourenço, M. P. Ciocci, F. Greco et al., "Traditional techniques for the rehabilitation and protection of historic earthen structures: The seismic retrofitting project," International Journal of Architectural Heritage, vol. 13, no. 1, pp. 15-32, 2019.

[5] M. Lutman, "Seismic resistance assessment of heritage masonry buildings in Ljubljana," International Journal of Architectural Heritage, vol. 4, no. 3, pp. 198-221, 2010.

[6] R. Marques and P. B. Lourenço, "Possibilities and comparison of structural component models for the seismic assessment of modern unreinforced masonry buildings," Computers \& Structures, vol. 89, no. 21-22, pp. 2079-2091, 2011.

[7] E. Mele, A. de Luca, and A. Giordano, "Modelling and analysis of a basilica under earthquake loading," Journal of Cultural Heritage, vol. 4, pp. 355-367, 2003.

[8] M. Mosoarca and V. Gioncu, "Failure mechanisms for historical religious buildings in Romanian seismic areas," Journal of Cultural Heritage, vol. 14, pp. 65-72, 2013.

[9] J. Radnic, A. Harapin, M. Smilovic, N. Grgic, and M. Glibic, "Static and dynamic analysis of the old stone bridge in Mostar," Gradevinar, vol. 64, pp. 655-665, 2012.
[10] A. Rafiee, M. Vinches, and C. Bohatier, "Modelling and analysis of the Nîmes arena and the Arles aqueduct subjected to a seismic loading, using the non-smooth contact dynamics method," Engineering Structures, vol. 30, no. 12, pp. 3457-3467, 2008.

[11] A. Taliercio and L. Binda, "The Basilica of San Vitale in Ravenna: investigation on the current structural faults and their mid-term evolution," Journal of Cultural Heritage, vol. 8, no. 2, pp. 99-118, 2007.

[12] G. Croci, "General methodology for the structural restoration of historic buildings: the cases of the Tower of Pisa and the Basilica of Assisi," Journal of Cultural Heritage, vol. 1, pp. 7-18, 2000.

[13] L. Krstevska, L. Tashkov, V. Gocevski, and M. Garevski, "Experimental and analytical investigation of seismic stability of masonry walls at Beauharnois powerhouse," Bulletin of Earthquake Engineering, vol. 8, no. 2, pp. 421-450, 2010.

[14] F. Portioli, O. Mammana, R. Landolfo et al., "Seismic retrofitting of Mustafa Pasha Mosque in Skopje: finite element analysis," Journal of Earthquake Engineering, vol. 15, no. 4, pp. 620-639, 2011.

[15] A. Saisi and C. Gentile, "Post-earthquake diagnostic investigation of a historic masonry tower," Journal of Cultural Heritage, vol. 16, no. 4, pp. 602-609, 2015.

[16] L. Binda, C. Modena, F. Casarin, F. Lorenzoni, L. Cantini, and S. Munda, "Emergency actions and investigations on cultural heritage after the L'Aquila earthquake: the case of the Spanish Fortress," Bulletin of Earthquake Engineering, vol. 9, no. 1, pp. 105-138, 2011.

[17] S. Cattari, S. Degli Abbati, D. Ferretti, S. Lagomarsino, D. Ottonelli, and A. Tralli, "Damage assessment of fortresses after the 2012 Emilia earthquake (Italy)," Bulletin of Earthquake Engineering, vol. 12, no. 5, pp. 2333-2365, 2013.

[18] D. F. D’Ayala and S. Paganoni, "Assessment and analysis of damage in L'Aquila historic city centre after 6th April 2009," Bulletin of Earthquake Engineering, vol. 9, no. 1, pp. 81-104, 2011.

[19] P. Foraboschi, "Church of San Giuliano di Puglia: seismic repair and upgrading," Engineering Failure Analysis, vol. 33, pp. 281-314, 2013.

[20] A. Penna, P. Morandi, M. Rota, C. F. Manzini, F. da Porto, and G. Magenes, "Performance of masonry buildings during the Emilia 2012 earthquake," Bulletin of Earthquake Engineering, vol. 12, no. 5, pp. 2255-2273, 2014.

[21] A. Ş. Çakmak, A. Moropoulou, and C. L. Mullen, "Interdisciplinary study of dynamic behavior and earthquake response of Hagia Sophia," Soil Dynamics and Earthquake Engineering, vol. 14, no. 2, pp. 125-133, 1995.

[22] Y. D. Aktaş and A. Turer, "Seismic evaluation and strengthening of Nemrut monuments," Journal of Cultural Heritage, vol. 16, no. 3, pp. 381-385, 2014.

[23] C. Alessandri and V. Mallardo, "Structural assessments of the church of the nativity in Bethlehem," Journal of Cultural Heritage, vol. 13, pp. 61-69, 2012.

[24] E. Juhásová, M. Hurák, and Z. Zembaty, “Assessment of seismic resistance of masonry structures including boundary conditions," Soil Dynamics and Earthquake Engineering, vol. 22, no. 9-12, pp. 1193-1197, 2002.

[25] R. Aguilar, M. F. Noel, and L. F. Ramos, "Integration of reverse engineering and non-linear numerical analysis for the seismic assessment of historical adobe buildings," Automation in Construction, vol. 98, pp. 1-15, 2019. 
[26] G. Bartoli, M. Betti, L. Galano, and G. Zini, "Numerical insights on the seismic risk of confined masonry towers," Engineering Structures, vol. 180, pp. 713-727, 2019.

[27] A. Ferrante, F. Clementi, and G. Milani, "Advanced numerical analyses by the Non-Smooth Contact Dynamics method of an ancient masonry bell tower," Mathematical Methods in the Applied Sciences, 2020.

[28] M. Orlando, M. Betti, and P. Spinelli, "Assessment of structural behaviour and seismic retrofitting for an Italian monumental masonry building," Journal of Building Engineering, vol. 29, Article ID 101115, 2020.

[29] G. Torelli, D. D’Ayala, M. Betti, and G. Bartoli, "Analytical and numerical seismic assessment of heritage masonry towers," Bulletin of Earthquake Engineering, vol. 18, no. 3, pp. 969-1008, 2020.

[30] A. Buzov, J. Radnić, N. Grgić, and G. Baloević, "Effect of the joint type on the bearing capacity of a multi-drum column under static load," International Journal of Architectural Heritage, vol. 12, no. 1, pp. 137-152, 2018.

[31] A. Buzov, J. Radnić, and N. Grgić, "Effects of several bolt parameters on the bearing capacity of a composite multidrum stone column under an earthquake," Composites Part B: Engineering, vol. 162, pp. 250-258, 2019.

[32] W. Romanceor, "Minčeta," 2015, http://hr.wikipedia.org/ wiki/Minčeta.

[33] L. Beritic,, The fortifications of the Town of Dubrovnik (In Croatian), JAZU, Zagreb, Croatia, 1955.

[34] Institute for the restoration of Dubrovnik, "The earthquake on 15 april 1979," 2015, http://www.zod.hr/eng/novost.php? $\mathrm{id}=14$.

[35] R. Console and P. Favali, "Study of the Montenegro earthquake sequence (March-July, 1979)," Bulletin of the Seismological Society of America, vol. 71, no. 4, pp. 1233-1248, 1981.

[36] S. Markušić, D. Herak, I. Ivančić, I. Sović, M. Herak, and E. Prelogović, "Seismicity of Croatia in the period 1993-1996 and the Ston-Slano earthquake of 1996," Geofizika, vol. 15, pp. 83-102, 1998.

[37] J. Radnić, "The expertise and rehabilitation project of the Minceta fortress (in Croatian)," Report No: T.D.K 03/13t, 2014.

[38] J. Radnic, D. Matesan, A. Harapin, M. Smilovic, and N. Grgic, "Numerical model for static and dynamic analysis of masonry structure," Advanced Structured Materials. Mechanics and Properties of Composed Materials and Structures, A. Oechsner, L. F. M. da Silva, and H. Altenbach, Eds., vol. 31, pp. 1-33, Springer, Berlin, Germany, 2012. 